\title{
Inhibition of histone deacetylation in 293GPG packaging cell line improves the production of self-inactivating MLV-derived retroviral vectors
}

\author{
Diana E Jaalouk ${ }^{1,5}$, Milena Crosato ${ }^{1}$, Pnina Brodt ${ }^{2,3}$ and Jacques Galipeau*1,4
}

\begin{abstract}
Address: ${ }^{1}$ Department of Medicine, Lady Davis Institute for Medical Research, McGill University, Montreal, Canada, ${ }^{2}$ Department of Medicine, McGill University Health Center, McGill University, Montreal, Canada, ${ }^{3}$ Department of Surgery, McGill University Health Center, McGill University, Montreal, Canada, ${ }^{4}$ Division of Hematology/Oncology, Jewish General Hospital, McGill University, Montreal, Canada and ${ }^{5}$ Department of GU Medical Oncology, Unit 1374, The University of Texas M. D. Anderson Cancer Center, P.O. Box 301439, Houston, Texas, USA

Email: Diana E Jaalouk -djaalouk@mdanderson.org; Milena Crosato - m.crosato@vif.com; Pnina Brodt - pnina.brodt@muhc.mcgill.ca; Jacques Galipeau* - Jacques.galipeau@mcgil.ca

* Corresponding author
\end{abstract}

Published: 07 April 2006

Virology Journal 2006, 3:27 doi:10.1186/1743-422X-3-27

This article is available from: http://www.virologyj.com/content/3/I/27

(C) 2006 Jaalouk et al; licensee BioMed Central Ltd.

This is an Open Access article distributed under the terms of the Creative Commons Attribution License (http://creativecommons.org/licenses/by/2.0), which permits unrestricted use, distribution, and reproduction in any medium, provided the original work is properly cited.
Received: 04 November 2005
Accepted: 07 April 2006

\begin{abstract}
Background: Self-inactivating retroviral vectors (SIN) are often associated with very low titers. Promoter elements embedded within SIN designs may suppress transcription of packageable retroviral RNA which in turn results in titer reduction. We tested whether this dominant-negative effect involves histone acetylation state. We designed an MLV-derived SIN vector using the cytomegalovirus immediate early enhancer-promoter (CMVIE) as an embedded internal promoter (SINCMV) and transfected the pantropic 293GPG packaging cell line.
\end{abstract}

Results: The SINCMV retroviral producer had uniformly very low titers $(\sim 10,000$ infectious retroparticles per $\mathrm{ml}$ ). Northern blot showed low levels of expression of retroviral mRNA in producer cells in particular that of packageable RNA transcript. Treatment of the producers with the histone deacetylase (HDAC) inhibitors sodium butyrate and trichostatin $A$ reversed transcriptional suppression and resulted in an average I06.3 $\pm 4.6-$ fold $(P=0.002)$ and I $5.5 \pm 1.3$ - fold increase in titer $(P=0.008)$, respectively. A histone gel assay confirmed increased histone acetylation in treated producer cells.

Conclusion: These results show that SIN retrovectors incorporating strong internal promoters such as CMVIE, are susceptible to transcriptional silencing and that treatment of the producer cells with HDAC inhibitors can overcome this blockade suggesting that histone deacetylation is implicated in the mechanism of transcriptional suppression.

\section{Background}

Retroviral vectors derived from C-type mammalian retroviruses are characterized by their ability to integrate into the chromosomal DNA of their target cells. For this reason, they have been a favored method of gene transfer into dividing cells in approaches where stable and sus- tained gene expression is desired or necessary. Conventional retroviral vectors resemble in their architecture their wild-type counterparts in that they retain cis-acting promoter sequences located in the 5 ' and the 3 ' long terminal repeats (LTRs) and the $\Psi$ signal that allows the packaging of recombinant RNA into viral particles $[1,2]$. 
Many retroviral vectors employ the use of inducible or tissue-specific promoters that are incorporated into the vector design to allow for regulated or targeted gene expression. However, the transcriptional activity of an embedded promoter can be compromised by interferences from the strong enhancer and promoter machinery in the flanking retroviral LTRs [3-5]. To bypass this problem, self-inactivating retroviral vectors (SIN) have been designed whereby the viral enhancer and/or promoter sequences are deleted from the U3 region of the 3'LTR. Following reverse transcription in transduced cells, the $3^{\prime}$ LTR deletions will be copied to the 5'LTR by template switch rendering the vector transcriptionally inactive [68].

SIN vectors have been successfully used to drive regulated transgene expression by inducible promoters $[9,10]$ and to confer restricted gene expression by cell type-or tissuespecific promoters [11-15]. Additionally, the SIN configuration results in relatively safer vectors for human gene therapy applications by reducing the risk of aberrant activation of cellular oncogenes adjacent to the integrated provirus site and by minimizing the risk of production of replication competent retroviruses (RCRs) [3,16]. For these reasons, SIN vectors have beenused in many cell and gene therapy applications including vectors derived from murine leukemia virus (MLV) [17-19], and lentivirus $[20,21]$. Despite their desired features, SIN vectors possess a number of limitations. They can be genetically unstable $[22,23]$ and may exhibit rescue of the U3-deletion in the 3' LTR by the intact 5'LTR due to recombination events $[6,24]$. To prevent such reconstitution events, hybrid 5 'LTRs have been used in which the U3 is replaced by nonhomologous enhancer or promoter sequences such as the cytomegalovirus (CMV) enhancer-promoter [25,26]. Moreover, SIN vectors are often associated with reduced titers which greatly limit their gene transfer efficiency $[27,28]$. As is the case for conventional retroviral vectors, low titers from SIN retrovectors could in part be due to transcriptional suppression of the expression of the necessary trans-components in packaging cells that are required for the production of the retroviral particles. Low titers from certain MLV-based SIN vectors have been also attributed to inefficient polyadenylation of the viral RNA due to extensive deletions made to the U3 region of the 3'LTR. Such deletions included the TATA box affecting the nearby $R$ region which is implicated in polyadenylation $[8,29]$.

We propose that interferences between elements of strong promoters incorporated within SIN retroviral vector designs and sequences in the 5'LTR can lead to suppression of retroviral RNA transcription which in turn results in reduction of SIN retrovector titers. We hypothesize that the mechanism of transcriptional suppression in SIN vectors involves the recruitment of histone deacetylases
(HDACs). To test this, we designed a SIN retroviral vector whereby a deletion was made to the $\mathrm{U} 3$ region of Moloney murine leukemia virus (Mo-MLV) 3'LTR removing most of the enhancer machinery that is intrinsic to the retrovirus. In this SIN template, a CMV promoter replaces the $\mathrm{U} 3$ region in the 5'LTR and drives expression of the retrovector mRNA in transfected packaging cell lines. As an internal promoter, we used the CMV immediate early enhancer-promoter (CMVIE) to drive expression of the enhanced green fluorescent protein (EGFP) reporter in transduced cells. The CMVIE is a very potent promoter and has been typically incorporated into retroviral and lentiviral backbones to drive strong transgene expression $[21,26]$.

Here, we show that transcription of retroviral RNA from the resultant SINCMV retrovector was suppressed in transfected 293GPG producer cells that had dramatically low titers ( $\sim 10^{4}$ viral particles per $\left.\mathrm{ml}\right)$. We further demonstrate that treatment of the SINCMV retroviral producers with the HDAC inhibitors sodium butyrate and Trichostatin A (TsA) reversed the transcriptional suppression and resulted in a significant increase in the SIN retroviral titer.

\section{Results \\ SINCMV retrovector design and increased retroviral RNA transcription with sodium butyrate treatment in transfected 293GPG producer cells}

A SIN vector was derived from a Mo-MLV-based vector, pLTRGFP, by creating a 311-bp NheI-SacI deletion to the 3'LTR, thus removing all the retroviral enhancers and the CAAT box (Figure 1A). Then, the SINCMV vector was made by incorporating the CMVIE enhancer-promoter into the construct upstream of the cDNA for EGFP reporter to drive strong transgene expression in transduced cells (Figure 1B). In this design, the CMV promoter in the hybrid 5'LTR drives the expression of a full-length $2.6 \mathrm{~kb}$ RNA transcript that can be packaged into retroparticles and a $\sim 2.1 \mathrm{~kb}$ spliced form that lacks the packaging signal $(\Psi)$. The internal CMVIE drives the expression of a shorter $\sim 1 \mathrm{~kb}$ transcript. Hence, retroviral RNA transcription from SINCMV proviral DNA in transfected producer cells should hypothetically result in 3 RNA transcripts, but only one is packageable (Figure 1B).

We then generated SINCMV retroviral producers by stable transfection of the $293 \mathrm{GPG}$ packaging cell line. The resultant polyclonal as well as isolated single clone producer populations were utilized to generate VSV-G pseudotyped retroviral particles and had very low titers in the range of $\sim 10^{4}$ viral particles per $\mathrm{ml}$ (see below). To test if strong promoter sequences incorporated within the SIN design can lead to suppression of retroviral RNA transcription which in turn results in reduction of SIN retrovector titers, total RNA was extracted from stable 293GPG-SINCMV 


\section{A. Control SIN vector proviral DNA}

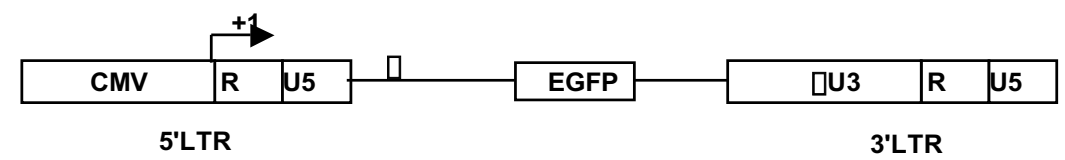

\section{B. SINCMV vector proviral DNA}

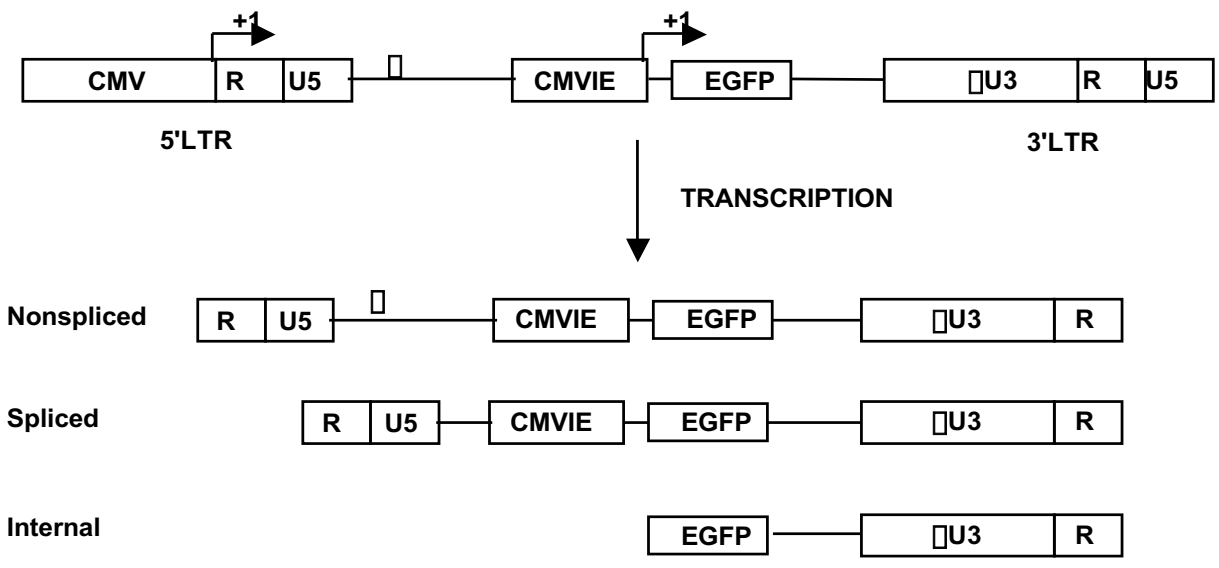

\section{SINCMV retrovector mRNA}

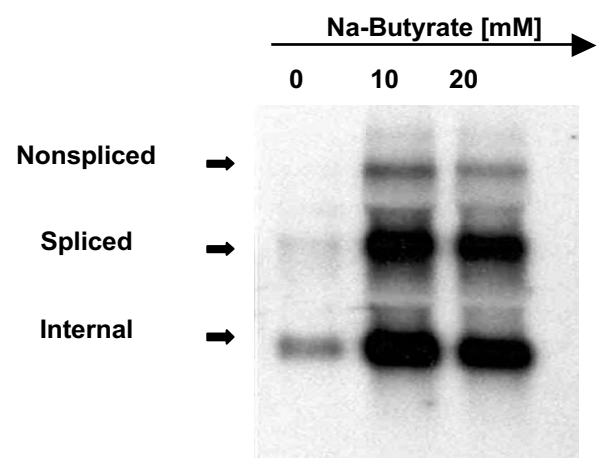

D. Ribosomal RNA

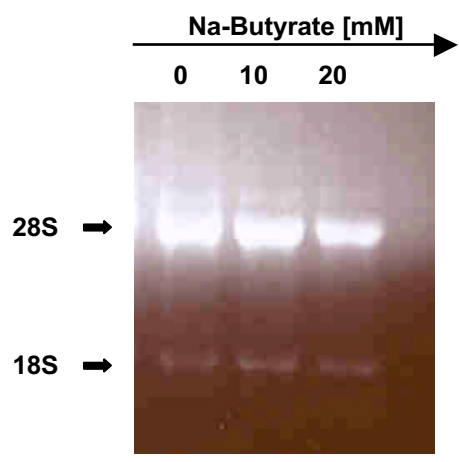

\section{Figure I}

SINCMV vector design and transcript expression in retroviral producer cells. A. The control SIN vector lacking an internal promoter has major deletions in the 3'LTR enhancer elements rendering its intrinsic promoter machinery transcriptionally inactive in transduced cells. B. Transgene expression in the SINCMV design is driven by the internal CMVIE promoter embedded upstream of the reporter EGFP. Three RNA transcripts are expected from SINCMV proviral DNA transcription in transfected packaging cells. The upstream CMV promoter in the 5'LTR drives the expression of a full-length $\sim 2.6 \mathrm{~kb}$ transcript that can be packaged into retroparticles and a $\sim 2.1 \mathrm{~kb}$ spliced form that lacks the packaging signal $(\Psi)$. The internal CMVIE drives the expression of a shorter $\sim 1 \mathrm{~kb}$ transcript. C. Hybridization with a P32- labelled EGFP probe done on total RNA extracted from SINCMV retroviral producers treated with butyrate indicated significant increase in the level of retrovector mRNA. D. Loading control of the 3 RNA samples is shown by ribosomal RNA staining with ethidium bromide. 
producer cells, loaded onto an RNA gel, and Northern Blot analysis for the SINCMV retrovector mRNA was done using a P $^{32}$-labeled GFP probe (Figure 1C). Expression of the 3 predicted retroviral RNA transcripts in these cells was very low with almost undetectable levels of the fulllength packageable transcript from the upstream CMV promoter. However, treatment of the producer cells with $10 \mathrm{mM}$ and $20 \mathrm{mM}$ sodium butyrate for $48 \mathrm{hr}$ resulted in a significant increase in the expression of the three transcripts and of particular importance of the non-spliced SINCMV retrovector mRNA which was undetectable in the untreated control cells. Loading of the 3 samples was controlled for by ribosomal RNA as shown by ethidium bromide imaging (Figure 1D).

\section{Increase in titer of SINCMV producers with sodium butyrate treatment and enhanced gene transfer into $A 549$ cells with improved SINCMV viral titers}

To determine if increased retroviral RNA transcription with sodium butyrate treatment, in particular that of the packageable retrovector transcript, would result in improved viral titer, SINCMV retroviral producers were treated with increasing doses of sodium butyrate for $48 \mathrm{hr}$, after which viral supernatants were harvested in fresh media. Following transduction of A549 cells, viral titer was measured as infectious viral particles per ml. Interestingly, $10 \mathrm{mM}$ butyrate treatment resulted in a significant $42.1 \pm 1.4$-fold increase in viral titer $(P=0.001)$ as compared to that of control untreated producers (Figure $2 \mathrm{~B}$ ). Moreover, the increase in SINCMV retroviral titer was dose-dependent. A maximal $106.3 \pm 4$.6-fold increase in titer was obtained with $20 \mathrm{mM}$ sodium butyrate treatment $(P=0.002)$ as determined from three independent experiments. By contrast, similar butyrate treatment of the producer cells for the control vector lacking the internal CMVIE promoter (Figure 2A) which had an average titer of $\sim 5 \times 10^{5}$ viral particles per $\mathrm{ml}$ resulted in only a modest $3.2 \pm 0.9$-fold increase with $10 \mathrm{mM}$ butyrate $(P=0.136)$ and $1.6 \pm 0.4$-fold increase with $20 \mathrm{mM}$ butyrate $(P=$ $0.299)$. Note that the upfront titer of the control SIN vector prior to butyrate treatment was 50-fold higher than that of the SINCMV vector.

A549 lung carcinoma cells, plated in 6-well dishes at the same number, were transduced with an equal sample volume of SINCMV retroviral supernatants collected from control untreated producers (Figure $2 \mathrm{C}$, a) as well as from producers treated with $10 \mathrm{mM}$ butyrate (Figure $2 \mathrm{C}, \mathrm{b}$ ) and $20 \mathrm{mM}$ butyrate (Figure 2C, c). Flow cytometry analysis of green fluorescence on gene modified cells revealed a striking increase in gene transfer efficiency into target cells using SINCMV retroviral supernatants from $10 \mathrm{mM}$ and $20 \mathrm{mM}$ butyrate treated producers whereby $68 \%$ and $97 \%$ of the target cells were positive for the EGFP reporter respectively. On the other hand, only $4.5 \%$ of A549 cells were transduced with an equal volume of the control supernatant from untreated producer.

\section{Increased histone acetylation in SINCMV producer cells treated with sodium butyrate}

To confirm that sodium butyrate treatment resulted in increased histone acetylation in SINCMV producer cells, histone proteins were isolated from control untreated producers as well as cells treated with increasing doses of sodium butyrate. The samples were then analyzed for their acetylation status using an Acid Urea Triton gel electrophoresis (Figure 3) that separates histone proteins based on charge density in addition to size and shape, hence allowing for the detection of posttranslational modifications such as acetylation. In such a gel, the addition of an acetyl group to a lysine residue on a histone protein renders the modified protein less positive and therefore it slows down its migration in the gel. Using Histone 4 as an indicator, we observed increased acetylation of histone proteins from SINCMV producer cells that were treated with $10 \mathrm{mM}$ sodium butyrate as compared to control, untreated producers. This increase in histone acetylation was even more evident in samples treated with 20 $\mathrm{mM}$ butyrate as can be clearly seen from the shift to greater levels of tri-acetylated and the appearance of tetraacetylated (Ac4) histone $\mathrm{H} 4$ as the dose of sodium butyrate increases.

\section{Increase in titer of SINCMV producers with Trichostatin A treatment}

To determine if the resultant increase in SINCMV retroviral titers with sodium butyrate treatment is specifically due to inhibition of histone deacetylation rather than a non-specific transcriptional upregulation effect, Trichostatin A which is a potent and specific inhibitor of histone deacetylation was assessed for its effect on SINCMV retroviral titer. Treatment of the producer cells with $\leq 1 \mu \mathrm{M}$ TsA for $48 \mathrm{hr}$ did not result in any significant increase in retroviral titer (Figure 4A). However, using higher drug concentrations, an average $15.5 \pm 1.3$-fold increase in titer was obtained with $3 \mu \mathrm{M}$ TsA treatment compared to control $(P$ $=0.008)$.

\section{Discussion}

Self-inactivating retroviral vectors are frequently designed with strong internal promoters to drive transgene expression in transduced cells, yet these designs are often associated with poor retrovector production. Low titers in the range of $10^{4}-10^{5}$ colony-forming units per $\mathrm{ml}(\mathrm{cfu} / \mathrm{ml})$ have been reported from SIN retrovectors that incorporated the SV40 promoter or the mouse metallothionein I (MT) promoter [6]. A dramatically low titer of $\sim 10^{3} \mathrm{cfu} / \mathrm{ml}$ was obtained from a SIN retrovector which had the TK promoter in sense orientation and the hMT inducible promoter in antisense orientation. In another study, a SIN 

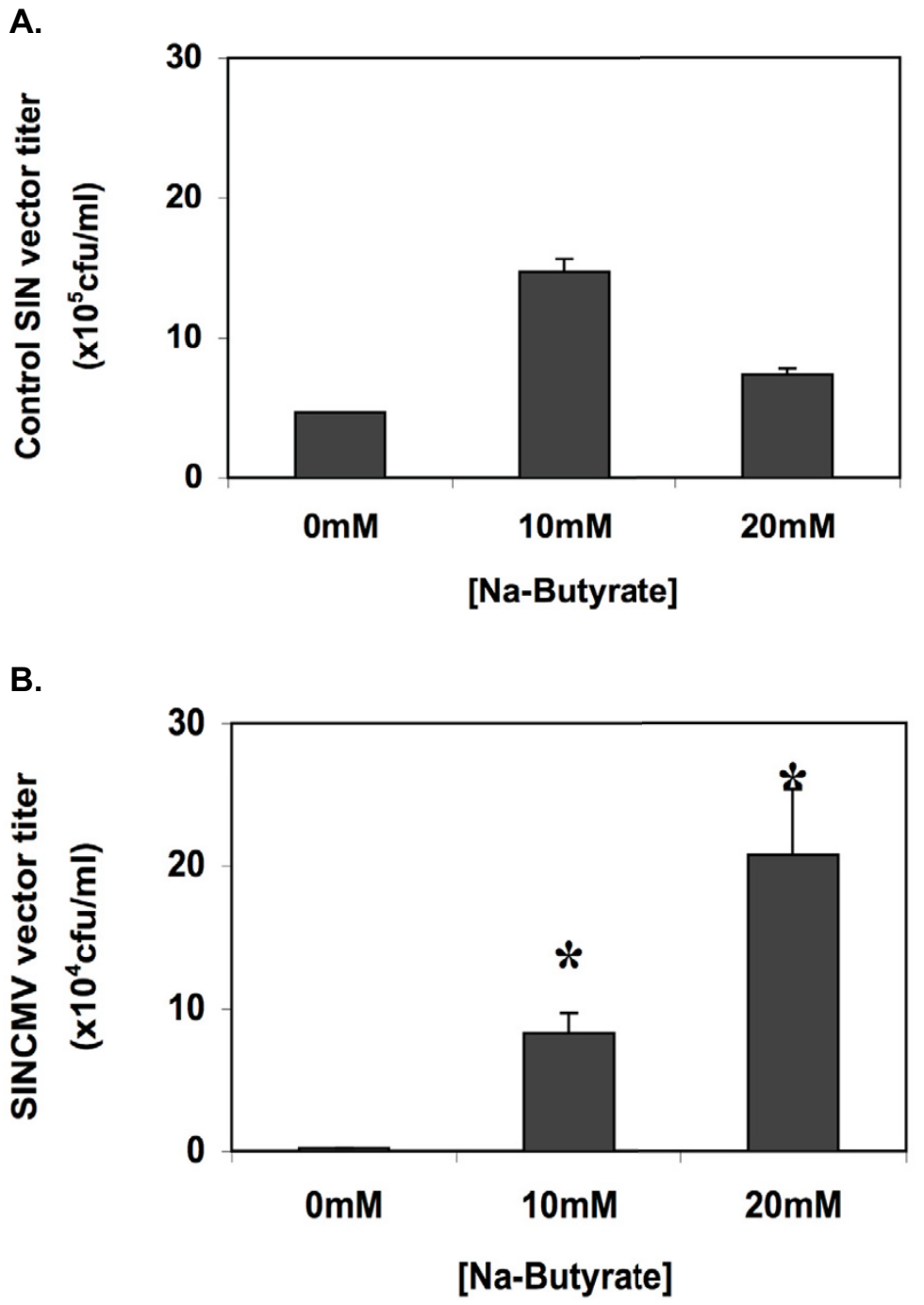

C.
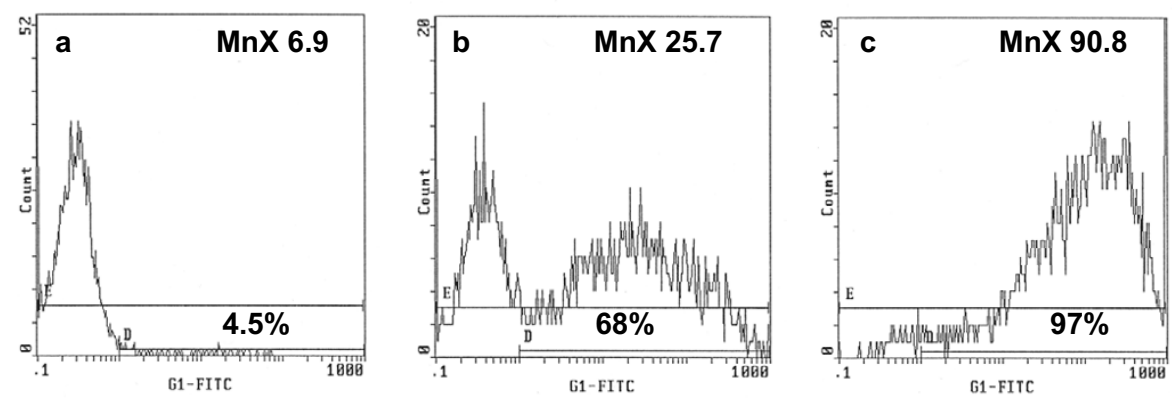

Figure 2

Titer of SINCMV retroviral producers treated with sodium butyrate and transduction of A549 cells with retrovirus from butyrate treated SINCMV producer cells. A. Treatment of control retroviral producer cells with the histone deacetylase inhibitor sodium butyrate for $48 \mathrm{hr}$ resulted in a modest $1.6 \pm 0.4$-fold increase in titer $(P=0.299)$. B. Treatment of SINCMV retroviral producer cells with sodium butyrate for $48 \mathrm{hr}$ resulted in a maximal $106.3 \pm 4.6$-fold increase in titer $(P=$ 0.002 ) that was obtained with $20 \mathrm{mM}$ butyrate. C. A549 lung carcinoma cells were transduced with same volume of retroviral supernatant that was collected from control-untreated SINCMV producers (a), producers treated with $10 \mathrm{mM}$ sodium butyrate (b), and $20 \mathrm{mM}$ sodium butyrate (c). \% EGFP positive cells for each sample and mean EGFP reporter expression in the gated population $(\mathrm{MnX})$ indicate a marked increase in gene transfer into target cells with supernatant from butyrate treated producers. 


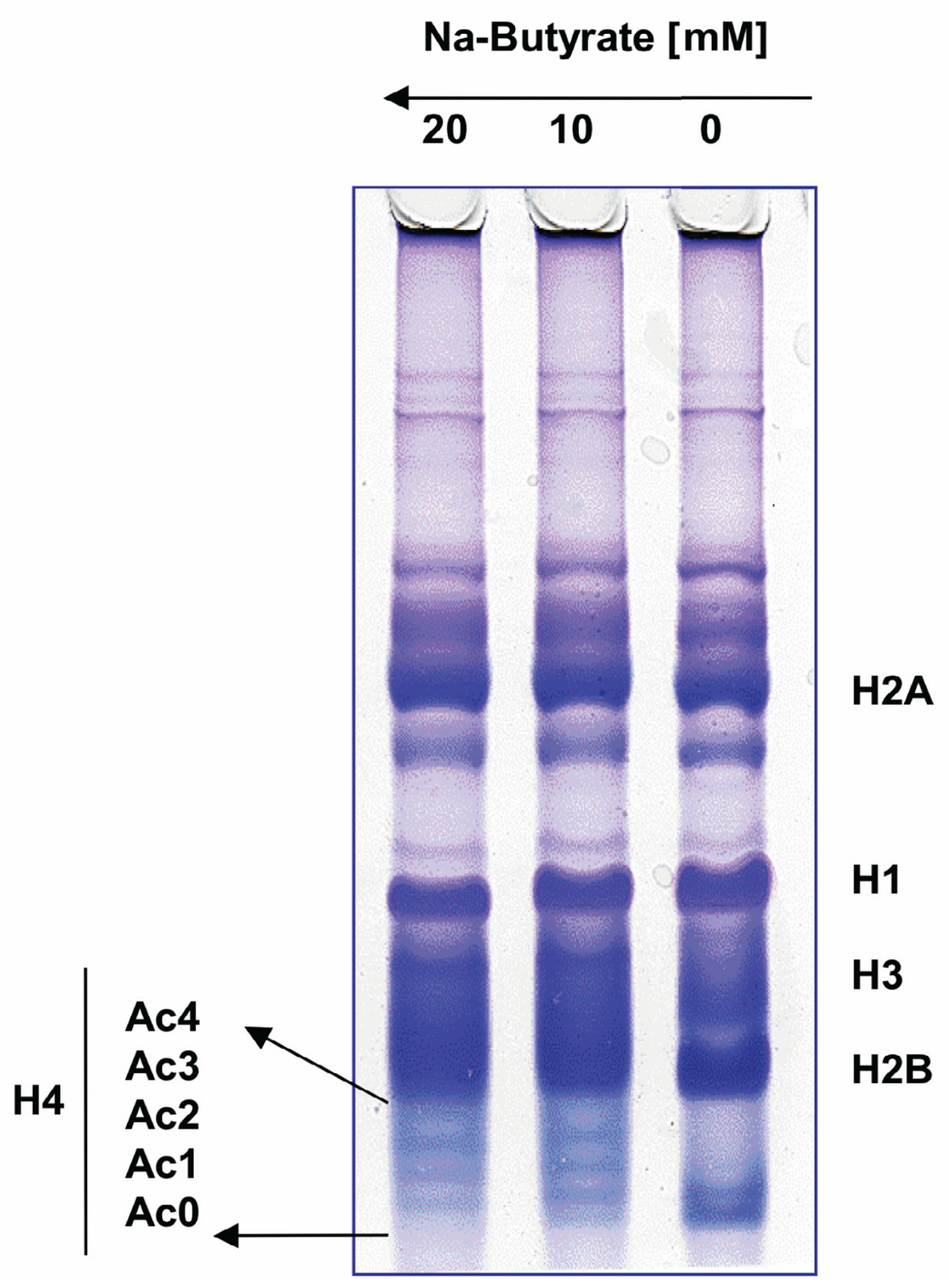

Figure 3

Histone gel assay on SINCMV producer cells treated with sodium butyrate. Treatment of SINCMV retroviral producer cells with increasing doses of sodium butyrate for $48 \mathrm{hr}$ resulted in increased histone acetylation as most obvious with histone $\mathrm{H} 4$. 


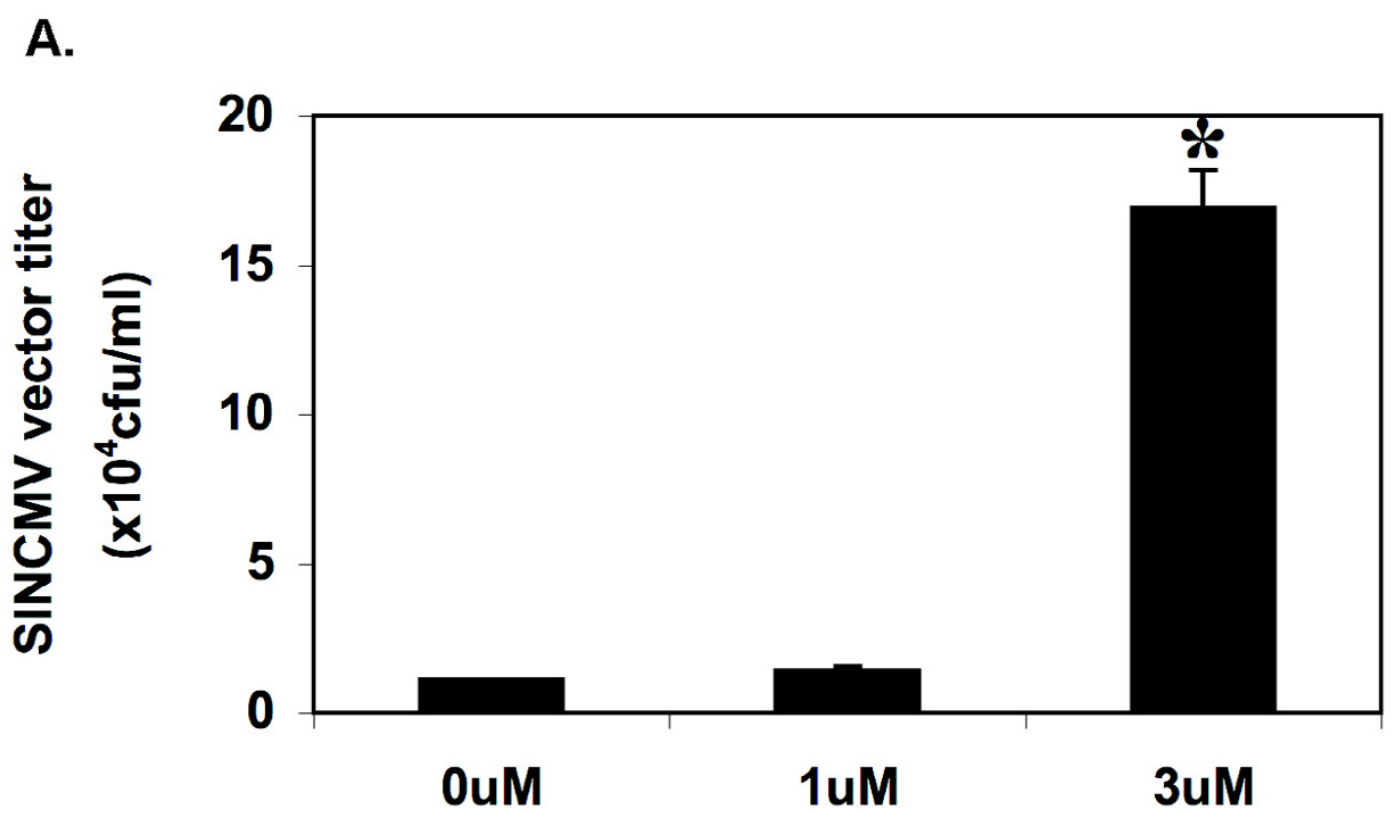

[TsA]

B.
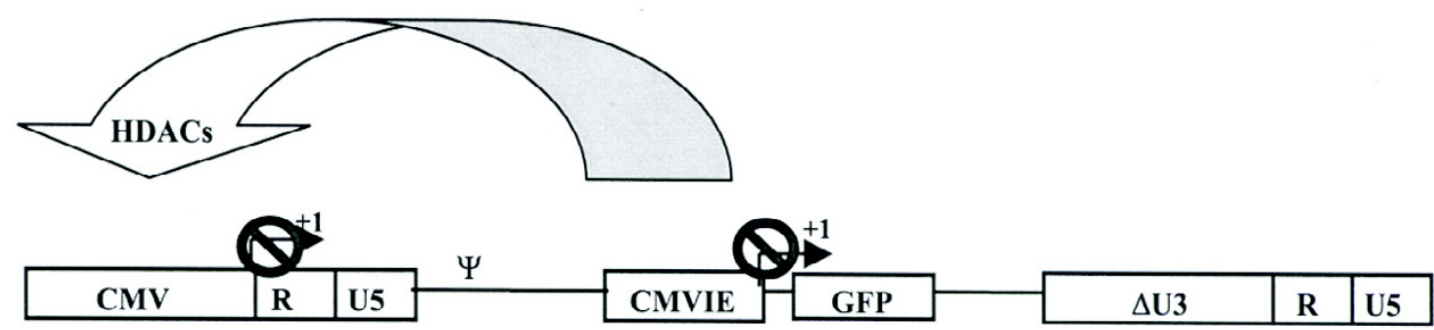

5'LTR

3'LTR

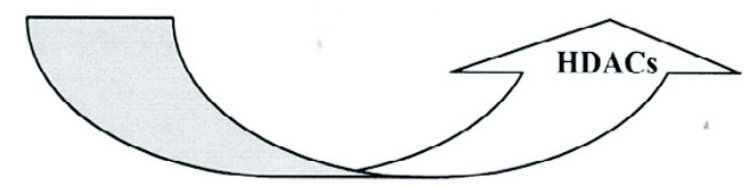

Figure 4

Titer of SINCMV retroviral producers treated with TsA and model depicting mechanism of transcriptional suppression in the SINCMV design. A. Treatment of SINCMV retroviral producer cells with the histone deacetylase inhibitor TsA for $48 \mathrm{hr}$ resulted in a maximal $15.5 \pm 1.3$-fold increase in titer $(P=0.008)$ that was obtained with $3 \mu M$ TsA. B. Interferences between strong elements in the internal CMVIE enhancer-promoter and the upstream CMV promoter in the 5'LTR lead to the recruitment of histone deacetylases (HDACs) which trigger an inactive chromatin conformation at the promoter sites leading to transcriptional suppression of the retroviral RNA. 
design with an internal hybrid promoter composed of the human beta-globin promoter and CMV enhancer sequences resulted in poor gene transfer efficiency likely due to lowered titers [27]. Moreover, Mo-MLV based retroviral vectors with hybrid LTRs incorporating large portions of the melanoma-specific murine tyrosinase enhancer/promoter also had titers in the range of $10^{3} \mathrm{cfu} /$ $\mathrm{ml}$ [28]. A later study reported very low viral titers of $10^{3} \mathrm{cfu} / \mathrm{ml}$ for SIN vectors in which the Mo-MLV enhancers were swapped by tandem repeats of the core element of the tyrosinase enhancer and the Mo-MLV promoter was substituted with the stronger SV40 promoter in an attempt to generate targeted retroviral vectors with higher levels of expression [30]. The authors attributed reduced titers in the latter studies to decreased efficiency of reverse transcription due to loss of a small part of the $\mathrm{R}$ region in the LTR. Their results also suggested a negative interference of the tyrosinase enhancer on the viral enhancer when the latter was retained in the 3'LTR. It has been also reported that the muscle creatinine kinase enhancer had a partial suppressive effect over the viral enhancer in the LTR [31]. Based on these findings, we speculated that interferences between elements of strong promoters incorporated within SIN designs and sequences in the 5'LTR can lead to suppression of retroviral RNA transcription which in turn results in reduction of titers from these vectors.

To assess the effect of promoter interferences within SIN retrovectors on viral RNA transcription and titer, we designed a Mo-MLV-based SIN vector by removing all the enhancers and the CAAT box from the 3 ' $\mathrm{U} 3$ region (Figure $1 \mathrm{~A})$. The TATA box and the $\mathrm{R}$ region were left intact to ensure efficient polyadenylation. Then, as an internal promoter, we incorporated the CMVIE enhancer promoter which is among the most potent enhancer-promoters known and has been typically incorporated into retroviral and lentiviral backbones to drive strong transgene expression [32,33]. The resultant SINCMV design (Figure 1B) which had low titers in the range of $\sim 10^{4}$ viral particles per $\mathrm{ml}$ has a hybrid 5'LTR in which a CMV promoter replaces the U3 region to ensure strong expression in transfected packaging cells and to minimize the risk of rescue of the SIN deletion in the 3'LTR. We expected interferences between the internal CMVIE and the upstream $5{ }^{\prime} \mathrm{CMV}$ in the SIN retrovector configuration as competitive inhibition between the two promoters was previously reported in plasmid constructs [34]. Indeed, very low levels of retroviral RNA transcripts derived from both promoters were obtained in producer cells transfected with SINCMV vector (Figure 1C). The expression of the full-length packageable transcript by the $5^{\prime} \mathrm{CMV}$ promoter was almost completely abrogated indicating a stronger interference from the internal CMVIE. Moreover, in the absence of butyrate, we observed 50-fold higher retroviral titers in a
SIN vector identical in all aspects to the SINCMV design except for the absence of the internal CMVIE promoter (Figure 2A). The sum of these observations strongly supports the notion that CMVIE is a potent cis-acting suppressor of promoters 5 ' to its location within a plasmid vector construct.

In recent years, there has been growing evidence that interference between promoter sequences are mediated by modifications to histone proteins which structurally and functionally interact with DNA. Such modifications result in modulation of chromatin conformation around a promoter site leading to transcriptional activation or suppression. In a previous study, results from P1 nuclease analysis strongly suggested that the CMVIE and the CMV sequences compete for the formation of active chromatin [34]. Additionally, other studies provided biochemical evidence that acetylation of histone proteins by histone acetyl transferases (HATs) at specific lysine residues on the amino-terminal tail domains results in active chromatin conformation $[35,36]$. Moreover, recent evidence linking several transcription factors such as Gcn5, CBP/p300, and TAFII250 to HAT activity strongly suggests a role for acetylation in transcriptional activation. On the other hand, deacetylation of histone proteins at a promoter site by histone deacetylases (HDACs) has been associated with transcriptional suppression. The mechanism is not well understood but several models have been proposed including disruption of the transcription initiation complex, or simply preventing its assembly, or changes in the higher-order structure of chromatin rendering it incompatible with transcription [37].

In fact, HDAC inhibitors have long been used as transcriptional activators. Butyrate, the first identified HDAC inhibitor [38], was used to induce gene expression from type C virus [39] and HIV LTR [40] in infected mammalian cells. However, at the time, it was not known by which mechanism butyrate treatment enhanced LTRdriven gene expression. More recent work demonstrated that HDAC inhibitors can activate transcription from integrated viral promoters $[41,42]$. Thus, we exploited the use of sodium butyrate for reactivation of retroviral RNA transcription in the SINCMV design. Our results show that treatment of the SINCMV producer cells with $10 \mathrm{mM}$ and $20 \mathrm{mM}$ sodium butyrate for $48 \mathrm{hr}$ resulted in a significant increase in the expression of the three viral RNA transcripts (Figure 1C). Of particular importance is the nonspliced packageable retrovector mRNA that is derived from the upstream 5 ' $\mathrm{CMV}$ promoter that was undetectable in the untreated control cells. Since the level of expression of packageable transcript is rate limiting for viral production, low levels of retroviral transcript expression in untreated producers could have contributed to the reduced viral titer obtained initially. Interestingly, treat- 
ment of the SINCMV retroviral producers with increasing doses of sodium butyrate not only reversed transcriptional suppression in the vector, but it also resulted in a significant increase in viral titer (Figure 2B). The effect was dose dependen. Improved titers resulted in a strikingly enhanced gene transfer into A549 lung carcinoma cells (Figure 2C). Furthermore, a histone gel assay confirmed increased histone acetylation in SINCMV producer cells treated with sodium butyrate (Figure 3 ).

HDAC inhibitors were used in previous studies to boost up production from conventional (non-SIN) retroviral [43-45] and lentiviral [46] vectors. In one study, production of a retroviral vector expressing the normal human cystic fibrosis transmembrane conductance regulator (CFTR) cDNA was significantly enhanced by sodium butyrate treatment of the producer cells with a simultaneous increase in the steady-state levels of LTR-driven fulllength retrovector RNA [43]. The authors suggested that the cDNA of CFTR caused an "ill-defined" interference with the LTR transcriptional activity that could have resulted in upfront low titers. However, it is worth noting that their retroviral vector had an internal simian virus 40 (SV40) promoter upstream of the neomycin selectable marker. Therefore, it is possible that the low titers associated with this vector could have also resulted from an interference effect between the internal SV40 promoter and the 5'LTR. Moreover, the viral supernatant was harvested from butyrate-containing media that could have lead to increased transgene expression from the integrated viral promoter in transduced cells. Therefore, not all the increase in expression in transduced cells could be attributed to an increase in viral titer and gene transfer.

Since histone hyperacetylation resulting from HDAC inhibition is only one of many cellular changes triggered by sodium butyrate treatment [38], TsA which is a highly specific and more potent HDAC inhibitor [47] was used to determine if histone acetylation is specifically involved in enhanced SINCMV titers. Our results show that treatment of the SINCMV retroviral producer cells with $3 \mu \mathrm{M}$ TsA resulted in a significant increase in titer indicating that histone deacetylation is indeed implicated in suppression of retroviral RNA transcription in the SINCMV design resulting in reduced titers (Figure 4A). Hereby, we propose a model depicting mechanism of transcriptional suppression in the SINCMV design. It is likely that interferences between strong elements in the internal CMVIE enhancer-promoter and the upstream promoter elements in the 5'LTR lead to the recruitment of histone deacetylases (HDACs) that triggers an inactive chromatin conformation at the promoter sites leading to transcriptional suppression of the retroviral RNA (Figure 4B). However, since the improvement in SINCMV titer with TsA treatment was less marked than that with butyrate, this is highly suggestive that other mechanisms are likely involved.

\section{Conclusion}

In conclusion, our results suggest that SIN retrovectors incorporating strong internal promoters are susceptible to significant transcriptional silencing in packaging cells leading to poor retroviral titers. Treatment of the producer cells with HDAC inhibitors can overcome this blockade suggesting that histone deacetylation is implicated in the mechanism of transcriptional suppression. These findings give us insights for improvement of SIN vector designs with important implications on SIN vector production in many cell and gene therapy applications.

\section{Methods \\ Cell lines and plasmids}

pJ6 2 Bleo plasmid and 293GPG retroviral packaging cell line [48] were generous gifts from Richard C. Mulligan (Children's Hospital, Boston, MA, USA). 293GPG cells were maintained in 293GPG media [DMEM (Gibco-BRL, Gaithesburg, MD), 10\%heat-inactivated FBS (Gibco-BRL)

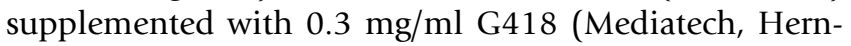
don, VA), $2 \mu \mathrm{g} / \mathrm{ml}$ puromycin (Sigma, Oakville, ONT), and $1 \mu \mathrm{g} / \mathrm{ml}$ tetracycline (Fisher Scientific, Nepean, ONT)]. A549, a human lung carcinoma cell line, was obtained from the American Type Culture Collection (ATCC, Manassas, VA) and was maintained in DMEM supplemented with 10\%heat-inactivated FBS and $1 \%$ penicillin-streptomycin.

\section{SINCMV retrovector design and synthesis}

We used a derivative of pLTRGFP [10] to generate the SINCMV design. pLTRGFP contains the CDNA for the enhanced green fluorescent protein (EGFP) reporter and a full-length LTR whose U3 region is derived from MSCV and whose $\mathrm{R}$ and $\mathrm{U} 5$ regions are derived from PCMMPLZ, a MFG derivative. We derived a self-inactivating vector from pLTRGFP by creating a 311-bp NheI-SacI deletion to the 3 'LTR to remove all the enhancers and the CAAT box. The synthesis of SINCMV was as follows. The 655-bp insert encoding for the CMVIE enhancer-promoter was excised by AseI/Klenow and AgeI digest of a shuttle vector that was derived from pEGFP-C1 (CLONTECH, Palo Alto, $\mathrm{CA}$ ). This insert was ligated into the product of BglII/Klenow and AgeI digest of the NheI-SacI SIN-derivative in order to generate the SINCMV plasmid. Both control SIN and SINCMV vectors incorporate the CMV promoter in the 5'LTR that drives expression in transfected producer cells. Nucleotide sequences of the mutated 3'LTR and the inserted CMVIE promoter were confirmed by DNA sequencing (GenAlyTic Inc., University of Guelph, ONT). 


\section{Generation of the retroviral producers}

The retroviral producers were generated by stable transfection of the 293GPG packaging cell line as previously described [10]. In brief, stable producer cells were generated by co-transfection of $5 \mu \mathrm{g}$ FspI-linearized control SIN

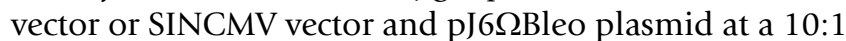
ratio. Transfected packaging cells were subsequently selected in 293GPG media supplemented with $100 \mu \mathrm{g} / \mathrm{ml}$ Zeocin (Invitrogen, San Diego, CA) for 3-to-4 weeks. Resulting stable polyclonal as well as isolated single clone producer populations were utilized to generate VSV-G pseudotyped retroviral particles. We selected producer clone 4 to perform subsequent experiments with butyrate. TsA experiments were performed on the polyclonal producer population to rule out any clonal effect that may have attributed to increased titers from producer clone 4 with butyrate treatment.

\section{Treatment of producers with histone deacetylase inhibitors for retroviral production}

Working stocks of $1 \mathrm{M}$ sodium butyrate were prepared from concentrated n-Butyric Acid (Acros Organics, NJ) in distilled water, then filtered with 0.2-micron syringe mounted filters (Gelman Sciences, Ann Arbour, MI), and stored at $4{ }^{\circ} \mathrm{C}$. Trichostatin A (TsA) stock (BIOMOL Research Laboratories, Inc., PA) was stored at $-20^{\circ} \mathrm{C}$. The treatment of control SIN or SINCMV producer cells with histone deacetylase inhibitors was as follows. The retroviral producer cells were maintained in 293GPG media in $100-\mathrm{mm}$ tissue culture dishes. At 70 to $80 \%$ confluency, the tetracycline-containing media was replaced with complete DMEM to allow for VSV-G expression and subsequently for retroviral production. One day post tetracycline withdrawal, either sodium butyrate in $\mathrm{mM}$ or TsA in $\mu \mathrm{M}$ concentrations were added to the cells in complete DMEM media for $48 \mathrm{hr}$, at $37^{\circ} \mathrm{C}$ and $5 \% \mathrm{CO}_{2}$. Afterwards, the drug-containing supernatant was discarded and fresh complete DMEM media was added to the producer cells to harvest retroviral supernatant in $24 \mathrm{hr}$. All viral supernatants were filtered with 0.45 -micron syringe mounted filters (Gelman Sciences) and stored at $-20^{\circ} \mathrm{C}$.

\section{Viral titer determination and RCR assay}

A549 target cells were plated in 6-well dishes at $4 \times 10^{4}$ cells per well and allowed to adhere overnight in complete media (DMEM, 10\%heat inactivated FBS, and 50 units/ml Pen/Strep) at $37^{\circ} \mathrm{C}$ and $5 \% \mathrm{CO}_{2}$. The following day, the overlaying medium was aspirated and replaced with $1 \mathrm{ml}$ per well of serial dilutions in complete DMEM media of the viral sample supplemented with $6 \mu \mathrm{g} / \mathrm{ml}$ Polybrene (Sigma). Target cells were then incubated with the viral dilutions overnight at $37^{\circ} \mathrm{C}$ and $5 \% \mathrm{CO}_{2}$. Subsequently, they were washed with $2 \mathrm{ml}$ per well of phosphate-buffered saline and were then expanded in culture in complete DMEM media. Flow cytometry analysis (FACStar sorter,
Becton Dickinson, Mountain View, CA) was then performed on these samples within 5-to-10 days following transduction to ascertain retrovector expression and gene transfer efficiency as measured by EGFP fluorescence. The viral titer was calculated from the gene transfer values obtained with each viral dilution and expressed as infectious particles per ml. Viral preparations were devoid of replication competent retrovirus (RCR) as determined by the standard EGFP marker rescue assay performed on null A549 cells with conditioned supernatant collected from transduced A549 cells.

\section{RNA extraction from SINCMV retroviral producer cells}

Total RNA was extracted from stable 293GPG-SINCMV retroviral producer cells using TRIZOL reagent (GibcoBRL, Gaithersburg, MD) according to the manufacturer's specifications. In brief, cells from $90 \%$ confluent $10-\mathrm{cm}$ tissue culture dish were lysed with $1 \mathrm{ml}$ of the TRIZOL solution. RNA was then extracted with $100 \%$ chloroform and precipitated with $100 \%$ isopropanol at $-80^{\circ} \mathrm{C}$ for over $1 \mathrm{hr}$. The precipitated RNA was then washed with $75 \%$ ethanol, air-dried for $5 \mathrm{~min}$ and resuspended in diethylpyrocarbonate (DEPC)-treated water and stored at $-80^{\circ} \mathrm{C}$.

\section{Northern blot assay}

Samples of $10 \mu \mathrm{g}$ total RNA in loading buffer were heated at $60^{\circ} \mathrm{C}$ for $10 \mathrm{~min}$, then loaded onto a $1 \%$ agarose- $1.1 \%$ formaldehyde gel, and electrophoresed in $1 \mathrm{X}$ MOPS buffer for $3 \mathrm{hr}$ at 150V. Afterwards, the gel was photographed under UV exposure and the RNA was transferred overnight onto a Hybond ${ }^{\mathrm{TM}}-\mathrm{N}$ nylon membrane optimized for nucleic acid transfer (Amersham Pharmacia Biotech, Buckinghamshire, England) using 20X SSC transfer buffer. The blotted RNA was then UV cross-linked to the membrane and hybridized at $68^{\circ} \mathrm{C}$ using the ExpressHyb $^{\text {тм }}$ Hybridization Solution (Clontech, Palo Alto, CA) with a $\mathrm{P}^{32}$ labeled EGFP probe prepared by the random oligolabelling kit (Amersham Pharmacia Biotech, Piscataway, NJ). The hybridized blot was washed twice at $68^{\circ} \mathrm{C}$ with $2 \mathrm{X}$ SSC/0.1\% SDS and $0.2 \mathrm{X}$ SSC/0.1\% SDS respectively, then exposed to X-ray photographic film (Kodak X-Omat) at $-80^{\circ} \mathrm{C}$.

\section{Isolation of histone proteins from SINCMV retroviral producers}

The isolation of histone proteins was done with some modifications to a previously described procedure [49]. SINCMV retroviral producer cells were trypsinized from a confluent 100-mm tissue culture dish, washed with PBS, and spun at $1800 \mathrm{rpm}$ for $5 \mathrm{~min}$. The cell pellet was re-suspended and lysed in $1 \mathrm{ml}$ ice-cold Nuclear Buffer (NB) (0.25M sucrose, $0.2 \mathrm{M} \mathrm{NaCl}, 10 \mathrm{mM}$ Tris/HCl - $\mathrm{pH} 8.0,2$ $\mathrm{mM} \mathrm{MgCl}_{2}, 1 \mathrm{mM} \mathrm{CaCl}_{2}$, and $1 \%$ Triton X-100) supplemented with protease inhibitors (Complete, Mini, EDTAfree, Roche Diagnostics, Mannheim, Germany) and re- 
spun at $13000 \mathrm{rpm}$ for $1 \mathrm{~min}$ to pellet the nuclei. The nuclei-containing pellet was then resuspended and incubated in $100 \mu \mathrm{l}$ of $0.2 \mathrm{M} \mathrm{H}_{2} \mathrm{SO}_{4}$ at $4{ }^{\circ} \mathrm{C}$ overnight. Afterwards, the insoluble fraction was pelleted at $13000 \mathrm{rpm}$ for $10 \mathrm{~min}$ and the supernatant containing the histone proteins was transferred to a clean $1.5 \mathrm{ml}$ tube. The BioRad Protein Assay kit (Bio-Rad Laboratories, Hercules, CA) was used to determine the protein content in the supernatant. Histone proteins were then precipitated using $900 \mu \mathrm{l}$ ice-cold acetone at $-20^{\circ} \mathrm{C}$ overnight, and airdried for $5 \mathrm{~min}$ after spinning at $13000 \mathrm{rpm}$ for $10 \mathrm{~min}$. Finally, the isolated histone proteins were re-suspended to $5 \mu \mathrm{g} / \mu \mathrm{l}$ in Acid Urea (AU) sample buffer (8M urea, 10\% glycerol, 5\% acetic acid, and 2\% w/v methyl green dye).

\section{Acid Urea Triton (AUT) gel electrophoresis}

Analysis of histone acetylation was performed using Acid Urea Triton (AUT) gel electrophoresis that was done with little modifications to procedures described previously $[49,50]$. We used a gel (Mini PROTEAN II-Bio-Rad) that consisted of $12 \%(\mathrm{w} / \mathrm{v})$ acrylamide, $0.08 \%$ bisacrylamide, $5 \%$ acetic acid, $8 \mathrm{M}$ urea, $6 \mathrm{mM}$ Triton X-100 and polymerized with TEMED and 25\% ammonium persulfate (APS). After polymerization, the gel was pre-run for $2 \mathrm{hr}$ in 5\% acetic acid buffer at 200V. Then, fresh 5\% acetic acid was used and $30 \mu \mathrm{g}$ of each sample was loaded onto the gel and electrophoresed at $135 \mathrm{~V}-200 \mathrm{~V}$ until the bromophenol blue dye migrated out. Finally, the gel was stained for $2 \mathrm{hr}$ with $0.03 \%$ Coomassie Brilliant Blue R250 plus 50\% ethanol, and 10\% acetic acid. In order to visualize the protein bands, the gel was de-stained using $20 \%$ ethanol and $10 \%$ acetic acid.

\section{Statistics}

Unless otherwise specified, all results are reported as average of three independent experiments \pm standard error of the mean. Student T test was applied using Microsoft Excel software.

\section{Competing interests}

The author(s) declare that they have no competing interests.

\section{Authors' contributions}

DJ carried out the cloning and generation of the various vectors, retroviral production and titer assays, transduction and subsequent analysis of target cells, transcriptional assays, data acquisition and analysis, and drafted the manuscript. MC did the work relating to the histone gel assay, helped in the above experiments in tissue culture, and revised the manuscript. PB contributed to the conception of the designs in the study, acquisition of funding, and revised the manuscript. JG had substantial contribution to the conception of the study, the experimental designs, data analysis and interpretation, general supervision of the research, acquisition of funding, and critically revised the manuscript. All authors approved of the final manuscript version.

\section{Acknowledgements}

We thank Franca Sicilia (Jewish General Hospital, Montreal) for flow cytometry analysis. We also thank Dr. Wilson Miller (Lady Davis Institute for Medical Research, Montreal) for providing access to necessary equipment and reagents. Special thanks to Dr. Daniel Martineau (Faculté de Médecine Vétérinaire, Université de Montréal, Saint-Hyacinthe) for valuable advice and to Dr. Nicoletta Eliopoulos (Lady Davis Institute for Medical Research) for editorial assistance.

This work was supported in part by the Canadian Institutes for Health Research Grant MOP-I50I7 and by a National Cancer Institute of Canada Terry Fox New Frontiers Grant. Jacques Galipeau is a recipient of a Canadian Institutes for Health Research Clinician- Scientist award.

\section{References}

I. Barquinero J, Eixarch H, Pâerez-Melgosa M: Retroviral vectors: new applications for an old tool. Gene Ther 2004, I I:S3-9.

2. Dornburg $R$ : The history and principles of retroviral vectors. Front Biosci 2003, 8:d8I8-35.

3. Cullen BR, Lomedico PT, Ju G: Transcriptional interference in avian retroviruses--implications for the promoter insertion model of leukaemogenesis. Nature 1984, 307:24I-245.

4. Proudfoot NJ: Transcriptional interference and termination between duplicated alpha-globin gene constructs suggests a novel mechanism for gene regulation. Nature 1986, 322:562-565.

5. Wu X, Holschen J, Kennedy SC, Ponder KP: Retroviral vector sequences may interact with some internal promoters and influence expression. Hum Gene Ther 1996, 7:159-171.

6. Yu SF, von Rèuden T, Kantoff PW, Garber C, Seiberg M, Rèuther U, Anderson WF, Wagner EF, Gilboa E: Self-inactivating retroviral vectors designed for transfer of whole genes into mammalian cells. Proc Natl Acad Sci U S A 1986, 83:3। 94-3198.

7. Hawley RG, Covarrubias L, Hawley T, Mintz B: Handicapped retroviral vectors efficiently transduce foreign genes into hematopoietic stem cells. Proc Natl Acad Sci U S A 1987, 84:2406-24I0.

8. Yee JK, Moores JC, Jolly DJ, Wolff JA, Respess JG, Friedmann T: Gene expression from transcriptionally disabled retroviral vectors. Proc Natl Acad Sci U S A 1987, 84:5 197-520I.

9. Hwang JJ, Li L, Anderson WF: A conditional self-inactivating retrovirus vector that uses a tetracycline-responsive expression system. J Virol |997, 7 1:7|28-7|3|.

10. Jaalouk DE, Eliopoulos N, Couture C, Mader S, Galipeau J: Glucocorticoid-inducible retrovector for regulated transgene expression in genetically engineered bone marrow stromal cells. Hum Gene Ther 2000, I I:1837-1849.

II. Zhao-Emonet JC, Marodon G, Pioche-Durieu C, Cosset FL, Klatzmann D: T cell-specific expression from Mo-MLV retroviral vectors containing a CD4 mini-promoter/enhancer. J Gene Med 2000, 2:416-425.

12. Gough PJ, Raines EW: Gene therapy of apolipoprotein E-deficient mice using a novel macrophage-specific retroviral vector. Blood 2003, 101:485-491.

13. Werner M, Kraunus J, Baum C, Brocker T: B-cell-specific transgene expression using a self-inactivating retroviral vector with human CDI9 promoter and viral post-transcriptional regulatory element. Gene Ther 2004, I I:992-1000.

14. Dai C, McAninch RE, Sutton RE: Identification of synthetic endothelial cell-specific promoters by use of a high-throughput screen. J Virol 2004, 78:6209-622I.

15. Stover ML, Wang CK, McKinstry MB, Kalajzic I, Gronowicz G, Clark $\mathrm{SH}$, Rowe DW, Lichtler AC: Bone-directed expression of Col I al promoter-driven self-inactivating retroviral vector in bone marrow cells and transgenic mice. Mol Ther 200I, 3:543-550. 
16. Zaiss AK, Son S, Chang LI): RNA 3' readthrough of oncoretrovirus and lentivirus: implications for vector safety and efficacy. J Virol 2002, 76:7209-7219.

17. Kraunus J, Schaumann DH, Meyer J, Modlich U, Fehse B, Brandenburg G, von Laer D, Klump H, Schambach A, Bohne J, Baum C: Self-inactivating retroviral vectors with improved RNA processing. Gene Ther 2004, II:I568-I578.

18. Soriano P, Friedrich G, Lawinger P: Promoter interactions in retrovirus vectors introduced into fibroblasts and embryonic stem cells. J Virol 1991, 65:2314-2319.

19. Hafenrichter DG, Wu X, Rettinger SD, Kennedy SC, Flye MW, Ponder KP: Quantitative evaluation of liver-specific promoters from retroviral vectors after in vivo transduction of hepatocytes. Blood 1994, 84:3394-3404.

20. Koya RC, Kasahara N, Pullarkat V, Levine AM, Stripecke R: Transduction of acute myeloid leukemia cells with third generation self-inactivating lentiviral vectors expressing CD80 and GM-CSF: effects on proliferation, differentiation, and stimulation of allogeneic and autologous anti-leukemia immune responses. Leukemia 2002, 16:1645-1654.

21. Ramezani A, Hawley TS, Hawley RG: Lentiviral vectors for enhanced gene expression in human hematopoietic cells. Mol Ther 2000, 2:458-469.

22. Emerman M, Temin HM: High-frequency deletion in recovered retrovirus vectors containing exogenous DNA with promoters. J Virol 1984, 50:42-49.

23. Li Q, Emery DW, Fernandez M, Han H, Stamatoyannopoulos G: Development of viral vectors for gene therapy of beta-chain hemoglobinopathies: optimization of a gamma-globin gene expression cassette. Blood 1999, 93:2208-2216.

24. Olson $\mathrm{P}$, Temin HM, Dornburg R: Unusually high frequency of reconstitution of long terminal repeats in U3-minus retrovirus vectors by DNA recombination or gene conversion. J Virol 1992, 66:1336-1343.

25. Naviaux RK, Costanzi E, Haas M, Verma IM: The pCL vector system: rapid production of helper-free, high-titer, recom binant retroviruses. IVirol 1996, 70:570I-5705.

26. Julius MA, Yan Q, Zheng Z, Kitajewski J: $Q$ vectors, bicistronic retroviral vectors for gene transfer. Biotechniques 2000, 28:702-708.

27. Riviáere I, Brose K, Mulligan RC: Effects of retroviral vector design on expression of human adenosine deaminase in murine bone marrow transplant recipients engrafted with genetically modified cells. Proc Natl Acad Sci U S A 1995, 92:6733-6737.

28. Vile RG, Diaz RM, Miller N, Mitchell S, Tuszyanski A, Russell SJ: Tissue-specific gene expression from Mo-MLV retroviral vectors with hybrid LTRs containing the murine tyrosinase enhancer/promoter. Virology 1995, 2 | 4:307-313.

29. Zufferey R, Dull T, Mandel RJ, Bukovsky A, Quiroz D, Naldini L, Trono D: Self-inactivating lentivirus vector for safe and efficient in vivo gene delivery. J Virol 1998, 72:9873-9880.

30. Diaz RM, Eisen T, Hart IR, Vile RG: Exchange of viral promoter/ enhancer elements with heterologous regulatory sequences generates targeted hybrid long terminal repeat vectors for gene therapy of melanoma. IVirol 1998, 72:789-795

31. Ferrari G, Salvatori G, Rossi C, Cossu G, Mavilio F: A retroviral vector containing a muscle-specific enhancer drives gene expression only in differentiated muscle fibers. Hum Gene Ther 1995, 6:733-742.

32. Boshart M, Weber F, Jahn G, Dorsch-Hèasler K, Fleckenstein B, Schaffner W: A very strong enhancer is located upstream of an immediate early gene of human cytomegalovirus. Cell 1985 4I:52I-530.

33. Rotondaro L, Mele A, Rovera G: Efficiency of different viral promoters in directing gene expression in mammalian cells: effect of 3'-untranslated sequences. Gene 1996, 168:195-198.

34. Chen PH, Tseng WB, Chu Y, Hsu MT: Interference of the simian virus $\mathbf{4 0}$ origin of replication by the cytomegalovirus immediate early gene enhancer: evidence for competition of active regulatory chromatin conformation in a single domain. Mol Cell Biol 2000, 20:4062-4074.

35. Lee DY, Hayes J], Pruss D, Wolffe AP: A positive role for histone acetylation in transcription factor access to nucleosomal DNA. Cell 1993, 72:73-84.
36. Vettese-Dadey M, Grant PA, Hebbes TR, Crane- Robinson C, Allis $\mathrm{CD}$, Workman JL: Acetylation of histone $\mathrm{H} 4$ plays a primary role in enhancing transcription factor binding to nucleosomal DNA in vitro. Embo J 1996, I5:2508-25।8.

37. $\mathrm{Ng} \mathrm{HH}$, Bird A: Histone deacetylases: silencers for hire. Trends Biochem Sci 2000, 25: I2I-I26.

38. Riggs MG, Whittaker RG, Neumann JR, Ingram VM: n-Butyrate causes histone modification in HeLa and Friend erythroleukaemia cells. Nature 1977, 268:462-464.

39. Long CW, Suk WA, Snead RM, Christensen WL: Cell cycle-specific enhancement of type $C$ virus activation by sodium $n$ butyrate. Cancer Res 1980, 40:3886-3890.

40. Golub EI, Li GR, Volsky DJ: Induction of dormant HIV-I by sodium butyrate: involvement of the TATA box in the activation of the HIV-I promoter. Aids 1991, 5:663-668.

4l. Beato M: Chromatin structure and the regulation of gene expression: remodeling at the MMTV promoter. I Mol Med 1996, 74:7II-724.

42. Barka T: Effect of sodium butyrate on the expression of genes transduced by retroviral vectors. I Cell Biochem 1998, 69:20I-210

43. Olsen JC, Sechelski J: Use of sodium butyrate to enhance production of retroviral vectors expressing CFTR cDNA. Hum Gene Ther 1995, 6: I195-1202.

44. Pagâes JC, Loux N, Farge D, Briand P, Weber A: Activation of Moloney murine leukemia virus LTR enhances the titer of recombinant retrovirus in psi CRIP packaging cells. Gene Ther 1995, 2:547-55।.

45. Tobias CA, Kim D, Fischer I: Improved recombinant retroviral titers utilizing trichostatin A. Biotechniques 2000, 29:884-890.

46. Sakoda T, Kasahara N, Hamamori Y, Kedes L: A high-titer lentiviral production system mediates efficient transduction of differentiated cells including beating cardiac myocytes. J Mol Cell Cardiol 1999, 3I:2037-2047.

47. Yoshida M, Kijima M, Akita M, Beppu T: Potent and specific inhibition of mammalian histone deacetylase both in vivo and in vitro by trichostatin A. J Biol Chem 1990, 265:17174-17179.

48. Ory DS, Neugeboren BA, Mulligan RC: A stable human-derived packaging cell line for production of high titer retrovirus/ vesicular stomatitis virus $\mathbf{G}$ pseudotypes. Proc Natl Acad Sci U S A 1996, 93: I| 400-II406.

49. Roberge M, Th'ng J, Hamaguchi J, Bradbury EM: The topoisomerase II inhibitor VM-26 induces marked changes in histone $\mathrm{HI}$ kinase activity, histones $\mathrm{HI}$ and $\mathrm{H} 3$ phosphorylation, and chromosome condensation in G2 phase and mitotic BHK cells. J Cell Biol 1990, I I I:1753-1762.

50. Hardison R, Chalkley R: Polyacrylamide gel electrophoretic fractionation of histones. Methods Cell Biol 1978, I7:235-25I.

Publish with Biomed Central and every scientist can read your work free of charge

"BioMed Central will be the most significant development for disseminating the results of biomedical research in our lifetime. "

Sir Paul Nurse, Cancer Research UK

Your research papers will be:

- available free of charge to the entire biomedical community

- peer reviewed and published immediately upon acceptance

- cited in PubMed and archived on PubMed Central

- yours - you keep the copyright 